\title{
Junctional epidermolysis bullosa, generalized severe
}

INSERM

\section{Source}

INSERM. (1999). Orphanet: an online rare disease and orphan drug data base. Junctional epidermolysis bullosa, generalized severe. ORPHA:79404

Junctional epidermolysis bullosa, Herlitz-type is a severe subtype of junctional epidermolysis bullosa (JEB, see this term) characterized by blisters and extensive erosions, localized to the skin and mucous membranes. 